\title{
E-democracy and the Matter of Scale. Revisiting the Democratic Promises of the Internet in Terms of the Spatial Dimension
}

\author{
Marianne Kneuer • Mario Datts
}

Published online: 8 May 2020

(C) The Author(s) 2020

\begin{abstract}
The emergence of the Internet fueled euphoric - partially utopian-visions that can be summarized as democratic promises. In most cases, the normative and empirical discussion so far has considered e-democracy tools and their potential, regardless of the scale of interaction-be it local, national, or transnational-as a one-size-fits-all approach, assuming that what is applicable for the national level will be equally true for the subnational and transnational levels. We argue that the question of whether the Internet and digital tools can fulfill the democratic promises must be confronted in a more differentiated way, examining under which spatial conditions e-democracy is more likely to incentivize citizens to engage and to involve more citizens as well as marginalized citizens in public debates and decision making. The article introduces scale as a new element for a better theoretical understanding of e-democracy. We establish a conceptual framework that enables us to capture scale as distance in terms of territorial, cognitive, and affective distance. The spatial perspective brings an innovative spin to the somewhat petrified positions on the mobilizing or reinforcing effects of digital tools as well as a new theoretical argument for the debate on e-democracy in general.
\end{abstract}

Keywords Democracy · Internet · Online political participation · Digital media · Space $\cdot$ Distance

\footnotetext{
M. Kneuer $(\bowtie) \cdot$ M. Datts

Institute of Social Sciences, University of Hildesheim, Universitätsplatz 1, 31141 Hildesheim, Germany

E-Mail: kneuer@uni-hildesheim.de

M. Datts

E-Mail: mario.datts@uni-hildesheim.de
} 


\section{Digitale Demokratie und Größe. Neubewertung der demokratischen Versprechen des Internets im Lichte der räumlichen Dimension}

Zusammenfassung Das Aufkommen des Internets schürte euphorische - teilweise utopische - Visionen, die sich als demokratische Versprechen bezeichnen lassen. In der bisherigen normativen und empirischen Diskussion wurden digitale Beteiligungsinstrumente und ihr Potenzial in den meisten Fällen unabhängig von ihrem räumlichen Anwendungsbereich (lokal, national, transnational, international) betrachtet, wobei davon ausgegangen wird, dass das, was für die nationale Ebene zutrifft, auch für die subnationale und die transnationale Ebene gilt. Wir argumentieren, dass die Frage, ob das Internet sich positiv auf die Qualität der demokratischen Prozesse auswirkt oder nicht, differenzierter betrachtet werden muss, indem untersucht wird, unter welchen räumlichen Bedingungen E-Demokratie zu mehr Beteiligung führt. Der Artikel führt daher den räumlichen Maßstab als neues Element für ein besseres theoretisches Verständnis von E-Demokratie ein. Wir entwickeln einen konzeptionellen Rahmen, der es ermöglicht, räumliche Entfernung im Sinne von territorialer, kognitiver und affektiver Distanz zu erfassen. Die räumliche Perspektive bringt einen neuen Gedanken in die mittlerweile recht erstarrten Positionen zu den Effekten des Internets für die repräsentative Demokratie.

Schlüsselwörter Demokratie $\cdot$ Internet $\cdot$ Politische Online-Partizipation · Digitale Medien · Raum · Distanz

\section{Introduction}

The new information and communication technologies (ICTs) as well as the digitalization of communication have nurtured an array of high expectations. Thus, the emergence of the Internet fueled euphoric_-partially utopian-visions that can be summarized as democratic promises. These promises ascribed to the new technology a democratizing potential for empowering citizens, establishing new forms of citizens' participation and including more citizens in public debates and decision making, especially previously marginalized and disadvantaged ones (Rheingold 1993; Wilhelm 2000; Bimber 2003; Hindman 2009). Another thread of democratizing promises claimed the dehierarchization of politics in a networked public sphere radically diminishing the role of elites, disaffiliating institutions, and bypassing entrenched state actors as well as markets and state economies while also challenging the dominance of the classic media channels (Castells 2011, p. 22-25, 2012, p. 9-10; Hindman 2009, p. 154-156; Shirky 2011; Benkler 2006).

Eventually, ICT even seemed to facilitate new models of democratic rules such as deliberative democracy, democratic self-government, and liquid democracy (Rheingold 1993; Wilhelm 2000; Bimber 2003; Hindman 2009). These promises experienced an additional boost when, at the turn of the millennium, web 2.0 technology made way for overall connectivity and real-time interactivity in the ubiquitous virtual space, proliferating social platforms and digital tools of various kinds. On a micro level, the technological advance of web 2.0 was considered as offering unprece- 
dented tools for empowerment and online self-communication (van Dijck 2013, p. 11), blurring the roles of producer and user and creating the "produser" or the "citizen journalist." On a macro level, a revolutionary change was induced toward networked sociality as a new type of networked communication on the web (Castells 2000; van Dijck 2013, p. 5-9). This technologically based global connectivity implied other promises, namely the vision of a global web infrastructure, prone to establish a transnational community of netizens; and the idea of social platforms as alternative spaces beyond corporate or government influence (Benkler 2006; Castells 2012; Bennett 2003). On this basis, the potential expansion of the public sphere in terms of deterritorialization and dissolution of boundaries was discussed, implying the expectation of a global virtual agora with digital citizens. ${ }^{1}$

All of these different promises stirred by the Internet crystallize into two main bundles. One refers to the expectation of curing all those ills that the model of representative democracy, especially in the last two decades, has manifested-in a nutshell, the Internet as a vehicle for revitalizing or reforming democracy. The other bundle of promises refers to the transformation of the public sphere toward one that is globally networked on the basis of a reconfigured power distribution and deterritorialization.

This paper focuses on the democratic promises linked to the concept of e-democracy, cyberdemocracy, or digital democracy. While it is difficult to find a definition that would clearly delineate e-democracy conceptually (e.g., from digital communication in general), there is consensus about the fact that e-democracy "has something to do with the use of information and communication technologies (ICT) to enhance democratic structures and processes" (Coleman and Norris 2005; Shane 2012, p. 7). Thus, a common denominator for e-democracy is the idea of a potential enhancement of democratic quality. Besides the normative debate about the potential of ICT for democratic processes, a considerable number of studies focus on the broad array of particular e-democracy tools. Remarkably, though, the technological potential of the extensive connectivity and its implications for spatial configurations of democratic practices in the cyberspace has not achieved much attention so far (Slane 2007, p. 85). Understanding this technical connectivity as an enabling attribute for new and "better" democratic process, the spatial dimension adds an important piece to the puzzle of whether and how e-democracy tools really do improve overall democratic quality and to what extent. While theorizing on the correlation between size and democratic quality is certainly not a new issue for democracy studies (in particular, see Dahl and Tufte 1973), it is surprising that the recent research so far did not transfer this fundamental theoretical concern of scale to the concept of e-democracy. The spatial dimension has been accounted for only as an indicator of the access to ICT - "on the role that geographic location plays in unequal access" (Sylvester and McGlynn 2010, p. 64)—but has not been theorized beyond that aspect.

While it is remarkable that democracy and size and the trade-offs between different scales of polities remain undertheorized and empirical studies are rare, it seems even more striking that research on the Internet, digital media, and digital democracy

${ }^{1}$ For digital citizenship, see Coleman and Blumler (2009), Dahlgren (2009), Mossberger et al. (2008), and Shirky (2011). 
does not elaborate in a more intense way on space, distance, and territorial aspects. Theoretical work is needed in order to reflect on whether and how the meaning of these concepts has changed against the background of digital communication and interaction. Much more work is required to understand how the changed understanding of space and distance impact e-democracy as well as other political issues.

The interest of this paper is to expand the theoretical understanding of e-democracy and to suggest a model of e-democracy integrating the spatial dimension. We argue that the question of whether the Internet and digital tools can fulfill the democratic promises must be confronted in a more differentiated way, examining under which spatial conditions e-democracy is more likely to incentivize citizens to engage and to involve more citizens as well as marginalized citizens in public debates and decision making. The theoretical argument guiding this paper is that scale matters and that spatial dimension plays a role in making a difference for effective e-democracy processes. Thus, we claim that theorizing e-democracy should consider in a more systematic way the scale as an influential condition for the success (or lack thereof) of e-democracy and at what scale online tools are applied: locally, nationally, transnationally/regionally, or globally. According to this model, the assessment of the impact (or success) of e-democracy has to consider the level on which the tool is implemented. For assessing e-democracy tools or processes, we employ the two criteria Dahl and Tufke suggested in their referential work on size and democracy: the system's capacity to respond fully to the collective citizens and the citizens' effectiveness to influence and control the decisions of the polity (Dahl and Tufte 1973, p. 20). These two criteria have been revisited and transformed into the equivalent terms of "citizen participation" and "governance capacity" as input and output. The assessment of the impact of e-democracy tools would involve (a) on which scale citizens are (more) involved in the initiation, design, and implementation of decisions (input); and (b) on which scale and to what extent services and solutions better reflect the citizens' needs (output).

Based on our theoretical claim, our basic assumption for the empirical dimension is that the effects of e-democracy tools could vary according to the different scales. This explorative study suggests some theory-based hypotheses on this variation. The theoretical assumption that scale matters relates to relevant praxeological implications proposing that concepts for e-democracy could be more promising on one level and less so on another. In this sense, we expect that assessing the quality of e-democracy and the "success" of e-democracy-tools would yield different results depending on the level the tools are deployed on. Since the spatial scale is closely related to the jurisdictional ones, which can be defined as "clearly bounded and organized political units" (Cash et al. 2006), our theoretical assumptions point, not insignificantly, to different administrative levels that e-democracy tools are deployed on, e.g., towns (local level), nations (national level), and transnational or international organizations such as the European Union (EU) and the United Nations (UN; transnational/global level).

The paper first traces the most relevant threads of research discussing the normative and the descriptive debate. On this basis we then set out to expose conceptual thoughts on the spatial dimension of e-democracy, proposing a model for capturing the spatial dimension of e-democracy tools. Being mainly a conceptual endeavor, 
the following section formulates some hypotheses. We conclude with suggesting future pathways for research and for the practical dimension of online participation tools.

\section{The Internet, Democratic Promises, and Changing Cycles: Taking Stock of the Normative and the Empirical Debate}

The study of the democratizing potential of digital media often follows a normative or prescriptive approach-either net-optimistic or net-pessimistic overall-that hypothesizes an improvement (or not) in the quality of democracy. The emergence of the Internet has generated an extensive debate about its potential effects on democratic processes and fueled a range of expectations, some involving utopian hopes (Buchstein 1996; Hague and Loader 1999; Wilhelm 2000; Hindman 2009; Coleman and Blumler 2009; Dahlgren 2009; Diamond and Plattner 2012). It is held that online-enhanced interaction will increase transparency, making it possible to retrieve and offer more information; promote inclusion by giving social actors (especially marginalized ones) better opportunities to contribute to the formation of public opinion outside institutionalized channels and without the filtering function of traditional media; open up alternative opportunities for participation, allowing people to be more involved in political decision-making processes over the Internet; and strengthen the responsiveness of political actors by easier access to dialogue with representatives on social media.

Against the background of increasing political disenchantment among citizens, the perceived disconnection between citizens and politicians, and the loss of trust in political institutions that can be observed in established democracies in recent decades, e-democracy has been regarded (and often overstated) as a panacea capable of curing democratic fatigue and revitalizing or modernizing democratic processes (Coleman and Blumler 2009; Kneuer 2013). The main stands of this literature involve promises, namely theoretically driven expectations about how digital media can strengthen democratic principles and processes, above all by "lowering the costs of communication, association, and participation" (Xenos and Moy 2007, p. 706; see also Rheingold 1993). Hence, these promises of more inclusion, participation, transparency, and responsiveness turned e-democracy into a theoretically and practically compelling concept. The normative debate on e-democracy envisages the potential role of ICT for curing ailments of representative democracy by complementing or upgrading democratic processes on the basis of online tools.

In a similar vein, social media is credited with creating new opportunities for civil society, social movements, or even new actors (grassroots movements) to make their voices heard and influence the public agenda (McCaughey and Ayers 2003; van de Donk 2004; Castells 2012; Gerbaudo 2012; Kneuer and Richter 2015). In regard to social media use, the expectation was that the features of connectiveness and interactivity of web 2.0 technology would not only enhance collective action but morph into "connective action" (Bennett and Segerberg 2013). A strong argument was made pointing to the potential of social media giving voice to those who had been excluded so far from public debates in traditional media. Examples like the 
protests in Arab countries, Occupy, the Spanish 15M, etc., especially corroborated the mobilizing power of social media. The inclusion of marginalized voices, however, proved to be a double-sword argument, as normative expectations predominantly referred to democratic voices against authoritarian regimes or citizens committed to liberal principles (Diamond 2010). What can be observed meanwhile is that the "same mechanisms that played such a huge role in the Arab Spring-social media's ability to give voice to the voiceless-is now empowering groups on the margins to challenge core democratic values." (Tucker et al. 2017, p. 52). Thus, social media increases the visibility of those opinions and attitudes that represent minority views and strengthens their options to be heard and influence the public agenda. But this effect proves true for democratic and antidemocratic or antisystemic, and liberal and antiliberal positions and groups in the same way. Therefore, the literature on social media and democracy reflects a similar conjuncture of optimistic and pessimistic assessments of the promises of ICT as the debate on e-democracy.

Another thread of this normative debate advocating for alternative forms of democracy, such as deliberative democracy, direct democracy, or liquid democracy, considered ICT as a way of facilitating the transfer of these theoretical models into practice (Barber 1998; Buchstein 1996; Dahlgren 2013). Even the vision of citizens' self-government - evoking the Athenian ideal of a virtual agora or ecclesia-gained renewed relevance as a possible model for future democracy (Shapiro 2000). While these models of democracy are principally thought to replace representative democracy, recent literature considers them an additional element within representative democracy, such as online deliberative formats or online consultation (Coleman and Shane 2012).

Dystopian views refer to the fact that access to communication tools might rather overwhelm citizens by the amount of information provided by the Internet and that it would become more and more difficult for them to sort out what is credible and accurate information. Likewise, scholars cautioned against a possible fragmentation or erosion of the public sphere (Buchstein 1996; Dahlgren 2005, 2009; Habermas 2008). The euphoric hope of approximating to the Habermasian ideal of online discourse-free from corporate influences, more inclusive, and more thoughtful-increasingly has been replaced by concerns of "echo chambers" (Garrett 2009; Barberá et al. 2015; Dubois and Blank 2018; Sunstein 2018), "filter bubbles" (Flaxman et al. 2016; Pariser 2012), incivility on the Internet (Papacharissi 2004; Anderson et al. 2014; Coe et al. 2014), and social bots (Ferrara et al. 2016). Moreover, the expectation of more inclusion was questioned, advancing even the opposite assumption of critical position in terms of increased inclusion of citizens (Sunstein 2009). Thus, the Internet would not eliminate exclusivity, gatekeepers, or elites but would create new ones or shift the exclusivity from the production of information to the filtering of it (Hindman 2009, p. 131-139).

Not only normative concerns but also empirical evidence seems to disprove the democratic promises of the digital age. However, what has not been discussed or tested so far is whether e-democracy has a different impact on different scales. Thus, the question is whether e-democracy tools might lead to different results in terms of enhancing democratic processes on different spatial-administrative levels. That is to say, there is no account so far of whether spatial dimensions matter for e-democracy. 
Because this spatial dimension is our main focus, the following literature review of empirical studies is structured in line with our argument (space matters), following a systematization according to different spatial-administrative levels concentrating on government-led activities.

\subsection{The Transnational Level}

Because top-down instruments on the transnational level are rather scarce, there is only limited evidence. The few empirical findings on transnational e-democracy projects indicate that digital tools are not capable of fulfilling any of the initial democratic promises on this level. A prominent transnational e-participation project is the European Citizens' Initiative (ECI). This instrument aims to give European citizens the opportunity to participate in law-making processes. There are, however, very high formal thresholds, since a successful initiative that gets examined by the European Commission needs one million participants from at least seven member states. This is why there have only been very few successful initiatives. Furthermore, those initiatives were not established by ordinary citizens, but by political organizations. This comes as no surprise, since gathering such a huge number of signatures needs a professional campaign. Although there is no information about the characteristics of those citizens participating in this process, "it is commonly believed that ECI participants tend to be well educated with a high interest in EU matters" (Rose et al. 2020, p. 211). Another EU participation instrument is Your Voice in Europe, which can best be described as an online consultation tool. This project, however, did not manage to realize broad participation (Rose et al. 2020, p. 218). Thus, the empirical results regarding the input dimension are rather disappointing.

\subsection{The National Level}

Even in countries where consultations are integrated into law-making on the national level-best-practice examples are provided by Estonia, Finland, and the United Kingdom-participation is rather disappointing. The Estonian portal OSALE (previously $T O M$ ) as well as Gov.uk show how far their holistic approaches link deliberation within citizens' initiatives or government-supported consultation with citizens' involvement in decision making (European Parliament 2016). A further example is the Finish New Citizen Initiative Act, which has allowed direct democratic participation via crowdsourcing since 2012 (European Parliament 2016, p. 17-19). From 2012 until 2015, nine successful initiatives were transmitted to the national parliament; however, only one became law, namely the introduction of same-sex marriage. The evaluation of this Finish law-making instrument revealed that in the case of this one successful initiative the mobilization was high (120,000 signatures in $24 \mathrm{~h}$ ), but neither the mobilized people nor the involved people reflected a representative picture of society, being predominantly young, well-educated urban males who supposedly were especially interested. Another example in Finland was the government's call for citizens to participate in the formulation of a law on off-road paths, which achieved a turnout of only 700 citizens (European Parliament 2016, p. 21-22). Mobilization deficits can also be found among the results of Bershadskaya et al. (2013, p. 75) 
comparing Russian, American, and British e-petition initiatives on the national level, demonstrating that none of the most popular initiatives in June 2013 reached even $1 \%$ of the population. The highest share of participants was realized by an initiative from the UK that got 248,000 votes ( $0.4 \%$ of population). Several studies show inequalities regarding gender, particularly the overrepresentation of men, for example in one of the national online participation tools in Portugal studied by Fedotova et al. (2012, p. 158) as well as in the results of Simon et al. (2017), who analyzed 13 digital initiatives from governmental actors and parties in Europe, Brazil, and Taiwan. The authors describe digital political participation as being dominated by those who are already politically active: well-educated, young, male, and from urban communities (Simon et al. 2017, p. 83). The examination of the UK Parliament's Public Reading Stage Pilot reveals, for example, that most of those citizens who used the opportunity to comment on proposed legislation online-which was the goal of the project-were those individuals who had already been active in offline campaigns before. Also, there was very little activity from citizens, and the few comments did not add any value for the parliament (Simon et al. 2017, p. 40-41). Another nationwide e-participation project from the UK (TheyWorkForYou) reveals better participation rates but shows a strong male bias, as well as strong participation of well-educated citizens with high incomes (Hennen 2020, p. 153). Almost the same seems to be true for a very similar online participation tool from Germany, giving citizens the chance to monitor their representatives (Hennen 2020, p. 157).

\subsection{The Local Level}

Several findings presented so far match the concerns that e-democracy tools reproduce already existing participation gaps on the national and transnational levels, that only privileged groups are getting involved rather than the broad masses, and that, therefore, the participation rate in general is rather low. In contrast to these rather disillusioning empirical findings, Simon et al. (2017) present more promising results on the local level. Better Reykjavik and Better Neighbourhoods, to name two local e-participation projects from Reykjavik (Iceland), succeeded in mobilizing almost $60 \%$ of the population to visit at least one of these two platforms. Interestingly enough, one successful idea that was processed by the city council was created by a 9-year-old girl asking for more school field trips. This finding should not blind us to the fact that most of the 15,962 registered users were older than 36 years. Youth participation has to be considered as particularly low (Simon et al. 2017, p. 43). Additionally, an evaluation of the platforms indicates that participation was biased toward well-educated citizens with higher salaries (Simon et al. 2017, p. 46). In contrast to the national version of this participation platform, however, the local versions seem to be more popular (Tiemann-Kollipost 2020, p. 184). One of the interviewed citizens feels that the local platforms are the best way to get people involved in digitally conducted decision-making processes because those kinds of platforms are related to issues from "your close environment" (Tiemann-Kollipost 2020, p. 185). Another local e-participation project described in the article of Simon et al. (2017) is located in Madrid (Decide Madrid). The overall awareness of the citizens in Madrid seems to be lower than for the platforms in Reykjavik (10\% of 
the Madrid population has registered). What is promising, however, is the finding of an almost equal gender split in the 2016 participatory budgeting exercise that was performed via Decide Madrid. Furthermore, there seems to be a less significant education gap than in Reykjavik (Simon et al. 2017, p. 49). An intruding empirical example for the mobilizing potential of local online participation projects is a participatory budgeting project in Paris. This platform generates "one of the highest levels of participation of any participatory budgeting process in the world" (Simon et al. 2017, p. 53). In 2016 158,964 people voted on a final selection of 219 ideas. Almost half of the participants were children, who took part in a special ballot (Simon et al. 2017 , p. 53). The participation rate for this local project was almost as high as, and in some cases even higher than, the national e-project Parlement et Citoyens, both in relative and absolute numbers. One of the few empirical studies dealing explicitly with the influence of size on local online participation was at least able to demonstrate "that citizens in small municipalities stand out as the most active" (Saglie and Vabo 2009, p. 397), even after controlling for individual resources and motivation.

One of the few studies that provide a comparative perspective of participation platforms located on different levels (local, regional, national) is a meta-analysis from the Global South, where the authors examined the participation rate of 23 platforms (Peixoto and Fox 2016). Their findings show that the seven examined e-democracy projects on the local level mobilized many citizens to participate. Two of the projects mobilized between 10,000 and 100,000 citizens, and one project even more than 100,000 citizens. Although the eight ICT projects on the regional level seemed to mobilize more citizens to participate in the process-with three projects mobilizing more than 100,000 citizens-one has to take into account that Peixoto and Fox (2016, p. 12) count the total number of participants. Interestingly enough, two of the three e-participation projects on the national level mobilized only a minimal number of citizens. It seems fair to conclude that the subnational and especially the local e-democracy-projects were more successful in mobilizing potential participants than the three examined projects on the national level. Aside from the participation rates, Peixoto and Fox (2016, p. 12) also examined the share of citizens' inputs addressed by the governments of the different scaled communities. In this case, we find the local governments to be much more open for citizens' issues than regional or national governments. In five of the seven examined e-democracy projects, $50 \%$ and more of citizens' issues were addressed. The local governments' responsiveness outperformed the regional and national governments very clearly. The higher share of citizens' inputs addressed might reflect the higher quality of inputs being made by the citizens. In sum, Peixoto and Fox (2016) show that e-democracy projects on the local level are able to mobilize more citizens than national projects and even as much as regional ones. Considering that we are looking at total numbers, one might state that the examined local projects from the Global South performed even better in mobilizing than was the case on the regional and national levels. Furthermore and without a doubt, the empirical findings of Peixoto and Fox (2016) show that the responsiveness to citizens' issues is much higher on the local than on the regional and national levels.

It has become apparent that empirical research so far has not produced consensus regarding the relative merits of the impact of ICT on democratic practice (Oser 
et al. 2013, p. 93): whether they would constitute a democratic uplift (mobilization hypothesis; see Rheingold 1993) or whether the same patterns as in the offline world are reflected and thus do not produce a democratic added value (reinforcement hypothesis; see Margolis and Resnick 2000). While there are findings suggesting that the Internet reinforces existing patterns of inequality, there is also evidence for the opposite, albeit less often (Mossberger et al. 2008). Hence, the debate on the impact of digital tools on democratic quality seems somewhat stuck in confirming one or the other assumption. Introducing the spatial dimension allows a more fine-grained and differentiated analysis, examining, for example, whether mobilization occurs more on one level than on the other. In most cases, the normative and empirical discussion so far has considered e-democracy tools and their potential, regardless of the scale of interaction-be it local, national, transnational or global-as a onesize-fits-all approach, assuming that what is applicable for the national level will be equally true for the subnational and transnational levels. Indeed, in theory building on e-democracy so far, the national level has been serving as the main point of reference, while the local and the transnational levels have been neglected and so have not achieved the same scholarly attention. Yet it is a mistake to think that concepts for national online offers could be transferred to the local or the transnational level.

One problem of the empirical research on e-democracy is that the extant-and doubtless very rich - threads of analysis on local, national, and transnational levels remain predominantly unconnected and thus do not speak to each other. This situation limits the cross-fertilizing from empirical-evidence studies produced in the last decades. What is needed is a conceptual framework that captures the spatial dimension of e-democracy and offers an explanatory approach for distance as a factor for the effectiveness of digital tools.

Finally, this nonconnectedness also refers to theory and practice. Despite the widespread negative evaluation of e-democracy projects by academics, practitioners still promote the idea that "harnessing the power of social and digital media to create new and more robust forms of democracy is alive and well" (Kreiss 2015, p. 2). One prominent example for this high hope is the entrepreneur Tim O'Reilly, who explained in a well-known white paper that "successful network applications are systems for harnessing collective intelligence" (O'Reilly and Battelle 2009, p. 2). Likewise, international organizations such as the UN act as norm entrepreneurs (Kneuer and Harnisch 2016) promoting e-government and e-participation as "development tools" (United Nations 2003, p. 4), referring to the less developed world. The World Bank (2002) emphasizes this potential in its E-Government Handbookfor Developing Countries. In the same spirit of transformative governance, the Organisation for Economic Co-operation and Development (OECD) developed the programmatic document The e-Government Imperative. In the last decade, this optimistic perspective on e-democracy is again very popular within the UN and is discussed in connection with the achievement of the Millennium Development Goals (United Nations 2010, p. 1, 2012, p. 1; see also Kneuer 2019). 


\section{Theorizing on the Scale of E-Democracy}

While broad literature has been generated on the normative expectations of e-democracy and likewise on the possible negative implications, less attention has been paid to models setting out, first, to establish a theoretical account of what e-democracy is and is not, and second, to suggest models that enable to do systematic — and comparative-analysis.

Interestingly, and in order to have a robust basis for workable policy recommendations, it was international organizations such as the OECD and UN that initiated important attempts of generating definitions and frameworks. Thus, Ann Macintosh (Macintosh 2004; OECD 2003) on behalf of the OECD took a meaningful step in developing an initial framework. Her conceptualization divides e-democracy into e-participation and e-voting (Macintosh 2004, p. 1; OECD 2003, p. 32). While e-voting is considered a technical problem (providing the technical conditions for allowing a general, direct, secret, equal, and free vote), e-participation entails technologically enhanced possibilities. Following this definition, Macintosh suggests characterizing dimensions of e-participation into (1) who should be engaged by whom, (2) with what technology, (3) for what period of time, and (4) in which stage of the decision making. Moreover, she includes criteria such as accessibility and resources. The most important differentiation refers to the three levels of engagement: enabling (support for accessibility and understandability of information by the audience), engaging (consulting with a wider audience and supporting deliberative debate on policy issues), and empowering (active participation and bottom-up ideas to influence the political agenda; Macintosh 2004, p. 3). These levels of participation correspond to the widely used model of information, consultation, and active participation (OECD 2001, p. 23). The UN e-Government Survey relies on a very similar model of emerging (information), enhanced (one-way or simple two-way communication), and transactional (two-way communication including transactions; United Nations 2003) participation. A slightly different definition proposes to conceive e-democracy as an umbrella notion for e-participation as well as e-government, while excluding e-voting (Kneuer 2016, p. 672; see also Kneuer 2019). Although it makes sense to analytically distinguish e-participation and e-government, as the latter is limited to top-down processes, e-government tools similarly can generate transparency and bolster accountability in policy-making processes, which can increase citizens' satisfaction and trust toward the government, thus strengthening the legitimacy of a polity (Clift 2004, p. 8-14; OECD 2003, p. 45). Therefore, and even if e-government primarily reflects a service and output-oriented concept, it implies a relevant component for the enhancement of democratic principles such as transparency and accountability and thus can be considered a driver for good governance. In short, e-democracy is understood as a concept comprehending e-participation (information, dialogue, monitoring, decision making) that can be government run, or at least government endorsed, or represent a grassroots activity as well as e-government (as exclusively a top-down approach; see Fig. 1).

One of the central issues in the research of e-democracy and e-participation refers to the impact of digital tools. Despite the legion of studies, it remains true that while scholars agree that the Internet is allowing new forms of political organizing and 


\section{E-Democracy}

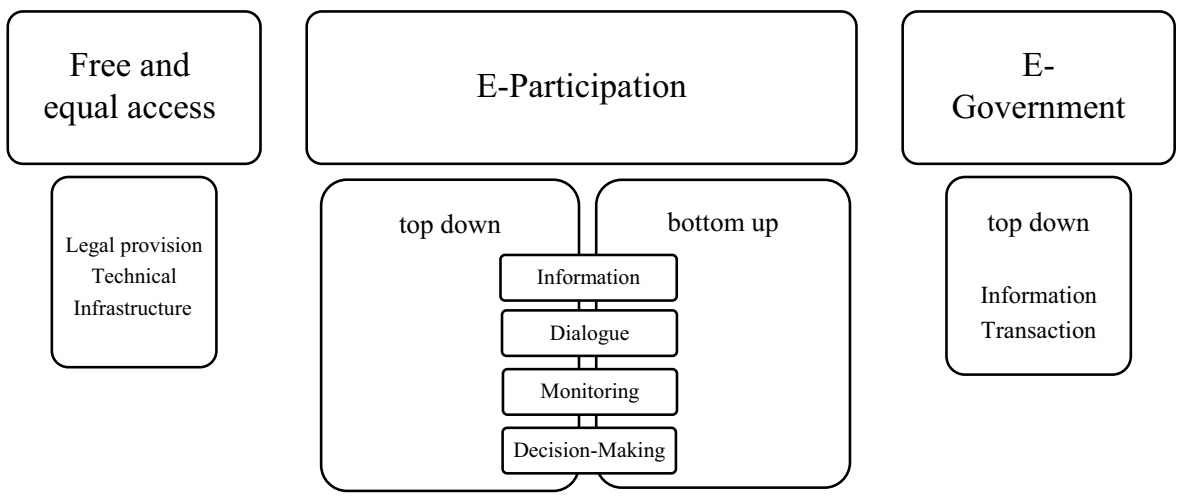

Fig. 1 Concept of e-democracy (Source: Kneuer 2016, p. 672)

participation, there continues to be disagreement about the importance of these changes (Hindman 2009, p. 10). Assessing the effect is empirically highly relevant for practitioners who might recalibrate the design of e-participation tools. But in the same way it is theoretically challenging, as such measurement of impact or "success" needs theory-based criteria.

As mentioned above, empirical research so far has not produced consensus regarding the relative merits of the mobilization and reinforcement theses. Empirical evidence for "successful" e-democracy practice is ambivalent. Our approach does not challenge these competing hypotheses about mobilization or reinforcement in general, but it begs for a more differentiated view on e-democracy and e-participation.

Few-better: to our knowledge, none-of the approaches setting out concepts or framework building of e-democracy have included a spatial dimension in the form of a scale. With regard to theory building, the technological potential of extensive connectivity and its implications for spatial configurations of democratic practices in cyberspace have not achieved much attention. This especially applies to political science. By introducing the spatial dimension into theory building, our research hinges on the results of geographers, who have, in contrast to social scientists, taken the "real-world geography" into consideration when studying online networks.

\subsection{The Spatial Dimension of the Internet}

One of the "most powerful visions" (Zook et al. 2004, p. 162) that the emergence of the Internet produced was that physical location, or rather distance, would become irrelevant (Cairncross 2001). Some scholars have argued that cyberspace is replacing physical space. The prediction of a "structural change" (Hampton 2015, p. 102) triggered by digital communication technologies that leads to a society struc- 
tured around shared interests and not shared places has a long tradition in the social sciences (Bell 1976; Hampton 2015). Castells is one of the most prominent representatives of this thesis. His theory of a networked society assumes that as digital networks are global, the "network society is a global society" (Castells 2011, p. 25). According to Castells (2011, p. 22-25), the superiority of networks characterized by the horizontal, not canted, form of societal organization against vertically organized structures can become visible only through the evolution of communication technology, i.e. digitalization.

Since aspects like digital divide, borders, and cultural differences (Stephens and Poorthuis 2015 , p. 88) are densely connected to the material world, this assumption is far from being uncontested. Stephens and Poorthuis (2015, p. 88), for example, state that a "large part of the early thinking on digital communities and its consequences can be labelled as 'naïve' with hindsight." This critical view of the "death of distance" (Cairncross 2001) thesis is widely shared in the geography field, since "in the face of 'globalization', questions of locality, sense of place and of identity in place matter now more than ever" (Withers 2009, p. 638). It becomes obvious that geographers have discussed the role of place and proximities in the era of the Internet since the early 2000s. Zook et al. (2004, p. 162-165) demonstrate that place remains a central factor in terms of access to and adoption of these new technologies. This is due to different forms of access and adoption, which depend on location-based factors such as culture, history, and regulatory issues (Zook et al. 2004, p. 157). Adams and Ghose (2003, p. 414) propose that ICTs are used to "build a sense of community and personal identity." This assumption leads to the thesis that technologies are used in a different manner in different places (Adams and Ghose 2003, p. 433). This points to the thesis of a society that is not structured around places but around shared interests, due to the Internet. This assumption ignores the fact that the physical location of individuals influences their interests. Thus, place matters even for virtual communities, as the spread of online forums for local communities demonstrates (Avram 2015). It seems that we are facing an increasing merging of digital and analog social networks, thus creating a hybrid space. Digital services such as Google Maps, Tinder, and FixMyStreet do not aim to establish systems that are independent from the "real" world but instead are strongly bound to it. Many successful digital services give users the opportunity to connect their digital and analog social networks (Meine 2017, p. 32). One might conclude that people do not want to disconnect from their real-world neighborhood by using digital technologies but rather to enrich their experience with it. It seems that "the online and offline layers of everyday life are inseparably interwoven" (Tiemann-Kollipost 2020, p. 187).

In stark contrast to geography, the political science discussion on the role of the spatial dimension in a digitalized world has just begun. There are only a few political scientists trying to connect the physical and the digital worlds. The discussion on place effects focuses on regional disparities in Internet access, which is one aspect of the popular concept of the digital divide (Mossberger et al. 2012, p. 772). Overall, this term refers to inequalities in the actual usage of recently emerged technologies, such as broadband Internet and associated technology services. Thus, literature on broadband in cities argue that "place matters" (Mossberger et al. 2013, p. 9). Such 
place effects can be found, with technology-savvy residential areas on one side and inexperienced areas on the other (Mossberger and Tolbert 2009), which might be due to socioeconomic differences among the residents. For the U.S.context, geo-ethnicity effects are also part of the explanation of the underlying causal mechanism of place effects (Kim et al. 2007). Place effects might mirror the geographic concentration of certain ethnicities with a low socioeconomic background, which is related to lacking commercial investment in goods and services in those areas, for example in Internet infrastructure (Mossberger et al. 2012, p. 776). Furthermore, "those who are less educated, or have limited Internet use within their social circles, including residents of poor communities, may not as readily learn about the potential uses of the web" (Mossberger et al. 2012, p. 777) and therefore avoid using it. Residents of poor neighborhoods may also lack the educational competence necessary to use Internet-based technology (Mossberger et al. 2012, p. 780). Also, those in low-paid employment might simply not be able to afford the price of (high-speed) Internet access (Mossberger et al. 2012, p. 778). The aforementioned causal mechanism of place effects for the use of new technologies might be the reason for the differences seen between rural and urban areas, as well as for inequalities within the overall Internet-savvy urban areas.

While the aforementioned authors, above all Mossberger et al., provide important evidence for the "place matters" argument in relation to the matters of access to the Internet, our concept aims to expand the argument beyond the dimension of technological infrastructure, addressing online interaction on the basis of e-democracy tools.

\subsection{Introducing Scale and Scope to the Concept of E-democracy}

As mentioned in the introduction, size is not a new issue to democracy studies. The question of which scale provides a better quality of democracy was raised by Aristotle and has been the subject of broad theoretical debates. In the more recent time period, the study of Dahl and Tufte (1973) submitted this topic to a fresh reevaluation, but the authors could neither completely confirm nor completely refute the centuries-old Aristotelian statement that democracy thrives better in small polities. A central conclusion of their study is that differences in the size of a particular kind of unit cannot predict certain benefits in a uniform way (Dahl and Tufte 1973, p. 42-43). Thus, the authors find that in several cases the same theoretical assumptions led to contradictory predictions about the consequences of size, all of them being quite plausible.

Quantitative studies bring in new evidence to revisit the classical narrative. Gerring and Zarecki (2012) show that size impacts the quality of democracy differently along different dimensions. They find that increasing the size of a polity may have negative consequences for participation and feelings of efficacy, while at the same time increasing the size of a polity may have positive consequences for electoral and liberal aspects of democracy, at least in the modern era (Gerring and Zarecki 2012, 
p. 15). Moreover, they indicate that in the context of discussing size and democratic quality, the subnational level needs further study. ${ }^{2}$

For scaling e-democracy, we build on the two main categories used by Dahl and Tufte (1973), namely system capacity (the capacity of the polity responding fully to the collective citizens) and citizens' effectiveness (the capacity to influence and control the decisions of the polity or input; Dahl and Tufte 1973, p. 20). Very convincingly, these two categories have been revisited and transformed into the equivalent terms of "citizen participation" and "governance capacity," also referred to as input and output (Røiseland and Vabo 2019; Scharpf 1999, 2003). Based on this, we suggest disentangling the spatial scales of e-democracy according to the input and output dimension. At the same time, this would enable impact assessment of e-democracy involving (a) on which scale and to what extent services and solutions better reflect the citizens' needs (output) and (b) on which scale citizens are (more) involved in the initiation, design, and implementation of decisions (input).

As briefly discussed above, predicting the benefits of size for democratic processes is contentious and still undertheorized for analog as well as for digital reality (Røiseland and Vabo 2019; Slane 2007). But at the same time, size itself is a multifaceted concept with different options for operationalization: geographic size, population size, population density, or a sort of surrogate measure such as density of social interaction, proximity to decision-making centers, etc. (Rose 2002, p. 830). Additionally, and referring to cyberspace, the density of interaction or group identification might have to be interpreted in a different way. But in contrast to theories that overstate the virtual space (Saco 2002), we hold that e-democracy tools are implemented in the context of a still hybrid interrelatedness between the offline and the online spaces. ${ }^{3}$

Following the idea of communication ecologies in the sense of Shane (2012, p. 4), every polity level has its own communication ecology linked to a specific set of attributes depending on the flow of information, the agenda that drives the community, and identification with the polity. We consider one relevant factor for the variation in communication ecology: the scale. Connectiveness and access to the Internet are relevant prerequisites for being involved in e-consultation or e-decision making, but the conditions and criteria for why digital citizens or netizens do or do not engage obviously go beyond the sole connectivity. We hold that territorial, cognitive, and affective distance constitute factors for their engagement.

This threefold concept of distance is based on Coleman and Price, who indicate that with relation to findings on online consultation, distance in cyberspace refers to territorial and also to cognitive and affective distance and may even influence this perceived or real distance (Coleman and Price 2012, p. 28). While the authors do not elaborate further on this, in another work co-authored by Coleman and Blumler (2009), they present a pertinent typology of citizenship distinguishing between the

\footnotetext{
2 While Gerring and Zarecki (2012) specifically refer to the concept of electoral democracy in the Schumpeterian sense, recently Jörke (2019) discusses size and democracy in light of a republican and social democratic understanding of democracy.

${ }^{3}$ This reflects the argument of not a few in the field of digital democracy (see, for example, Chadwick 2013).
} 
concept of legal-judicial citizenship (official membership in a political community), political citizenship, and affective citizenship. For our purpose, the latter two types are especially relevant. Political citizenship refers to the fact that a citizen is more than an "officially recognized member of a community, but a potentially active constituent body politic" exerting political influence on his or her fellow citizens as well as on the political polity (Coleman and Blumler 2009, p. 5-6). For this role, three kinds of participation are used: information gathering, deliberation, and active effort to influence public policies and decisions. Affective citizenship has to be conceived of as feelings of civic belonging, loyalty, and solidarity, very much connected to the affective attachment to the polity and their members. This echoes work on online participation that underlines the emotional dimension of digital interaction (Dahlgren 2013, p. 25). The aspect of identity for online engagement proves to be equally relevant (Bennett and Segerberg 2012).

Building on this distinction of territorial, political, and affective citizenship, the scales described above are based not only on territorial distance, which has experienced a diminution due to digital connectedness, but also on cognitive and affective factors in terms of involvement in e-democracy. The cognitive closeness or distance is determined by (a) the degree of information and knowledge of the policy issues to be discussed or decided, (b) political interest, and (c) trust in the government of the polity. The affective closeness or distance refers to (a) the self-efficacy of the user (Does my voice count in this specific issue? Can I influence this issue?) and (b) his or her concern (affectedness) about a certain issue (How much do I care about this issue? How affected am I by this decision?). Finally, (c) the identification with the polity and the feeling of belonging to the community is a factor (How strong are my bonds to the community? How important is it for me to contribute to this community?).

With regard to the impact of scale on the output dimension, we suggest responsiveness as a criterion since the government's reflection of citizens' needs can also be described as the "responsiveness of the rulers to the ruled" (Fuchs 1997). ${ }^{4}$ We do not argue that governance capacity or output dimension can be reduced to a government's responsiveness. Especially when governments rely on online consultation-or much more: connect it with law making-for providing collective solutions, responsiveness becomes a central factor. Thus, involving citizens in political processes by online tools requires that politicians and officials show the adequate readiness and responsiveness when it comes to putting policies in place (Coleman and Price 2012 , p. 29). An increase of democratic quality can be achieved only if citizens not only get offered additional space for exchanging their concerns and ideas but also perceive that government institutions and officials take these concerns seriously and include them in their solutions. Following this idea, output would be determined by

\footnotetext{
4 We cannot dwell on the plethora of literature concerning responsiveness here. We are aware, however, that responsiveness is sometimes assigned to input and output and sometimes only to output. Dahl very much focuses on the input dimension, but at the same time considers the output by incorporating it via the democratic process itself (Dahl 1989, p. 108-118). For a critical account of responsiveness as a democratic category, see Lauth (2011).
} 

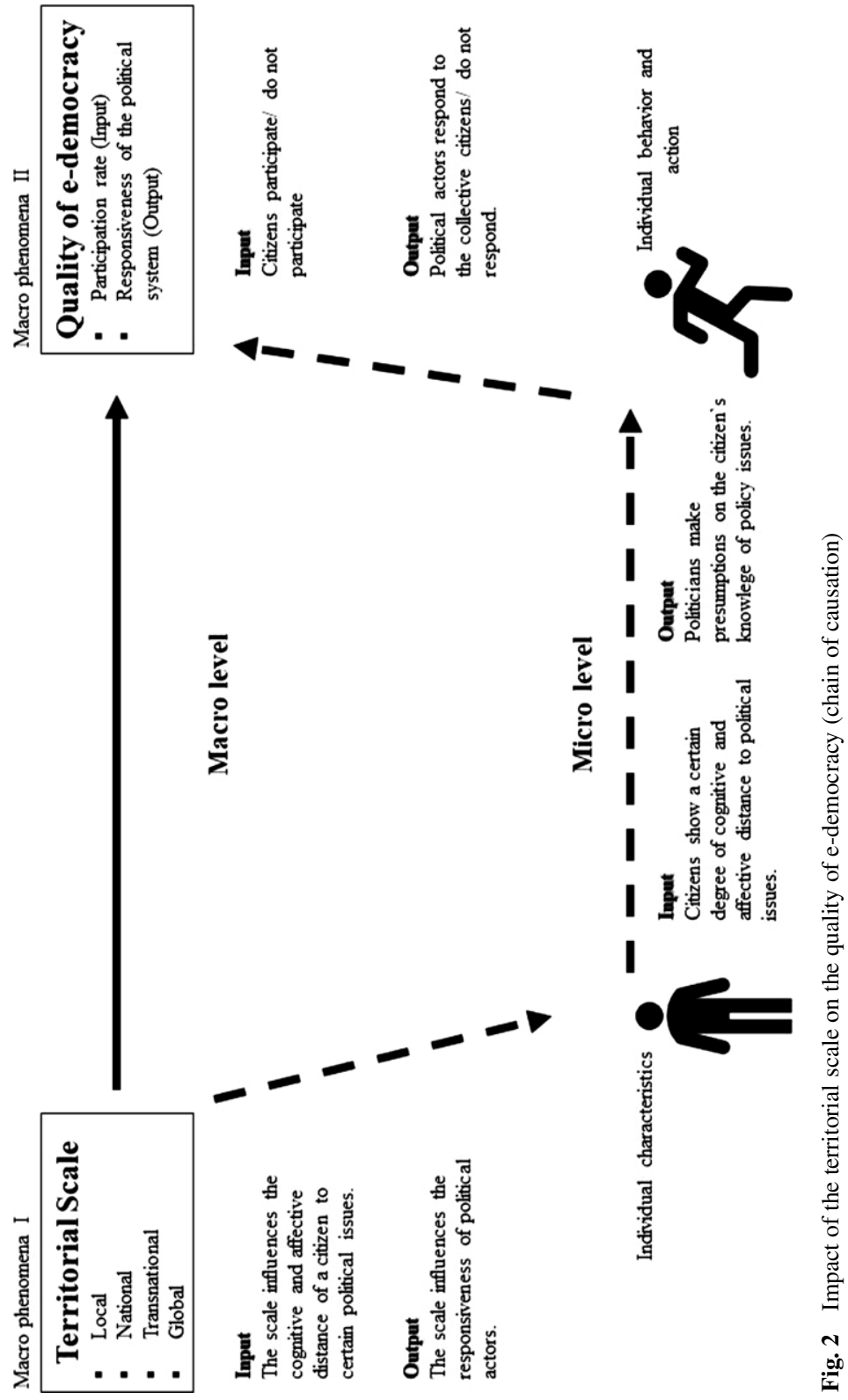

"the share of citizens' inputs addressed" (Peixoto and Fox 2016, p. 12) by those in power (see Fig. 2).

Based on the considerations made so far, we propose three general hypotheses, which deserve to be examined on an empirical basis. As a reminder, we refer only to e-democracy and not to all social media interactions. Furthermore, we exclude e-voting as conventional participation, and thus, for the advancement of our argument 
and for reasons of space, we focus on e-participation, the means of digital tools for information, consultation, monitoring, and decision making (see Fig. 1). Table 1 illustrates our key assumptions.

\subsubsection{Hypothesis I (Cognitive Distance Hypothesis)}

Regarding cognitive distance, we assume that users will have more knowledge and information about political issues and also more interest in influencing these issues on a local level than the national level, and relatively more knowledge on the national than on the transnational and global levels. It is quite plausible that Internet users have a higher level of knowledge about problems, policy, projects, etc., on the local level than on any other level, given the fact that global political issues bear a much higher complexity and thus are much more time-consuming to follow and fully capture. As trust can be considered a cognitive category along with knowledge (Hardin 1999; Røiseland and Vabo 2019), this aspect can be included in the assessment of cognitive distance. Moreover, evidence exists here from the comparison between the local and the national levels that informs about a higher trust in local officeholders than in national ones (Denters 2002). We would also suppose this linearity in terms of trust in officeholders. Thus, in terms of cognitive distance, the chain of causation would be as follows: The lower the cognitive distance, the better the prospect of getting involved in the initiation, design, and implementation of e-democracy processes (see Table 1).

\subsubsection{Hypothesis II (Affective Distance Hypothesis)}

Regarding affective distance, the picture might be different. We assume that selfefficacy as well as affectedness will be high on the local level and higher than on the national and transnational levels (such as EU consultation), as their governing entities would deal with specific issues that might not affect a broad number of users (as in Finland for same-sex marriage) or "technical" issues (as in Finland for off-road driving). On the global level, issues might be more abstract and more emotionalizing at the same time: The criticism of the global banking system and the global capitalist system by Occupy referred to a highly complex and abstract issue, but at the same time had a high potential for emotionalization. The same applies to climate change, which is highly complex but achieves a high level of affectedness and concern. Thus, the chain of causation regarding the affective distance would be

Table 1 Relationship between the spatial dimension and the performance of e-democracy

\begin{tabular}{|c|c|c|c|c|c|}
\hline \multirow[b]{2}{*}{ Scale } & \multirow[b]{2}{*}{$\begin{array}{l}\text { Territorial dis- } \\
\text { tance }\end{array}$} & \multirow[b]{2}{*}{$\begin{array}{l}\text { Cognitive } \\
\text { distance }\end{array}$} & \multirow[b]{2}{*}{$\begin{array}{l}\text { Affective dis- } \\
\text { tance }\end{array}$} & \multicolumn{2}{|c|}{$\begin{array}{l}\text { Performance of e-democ- } \\
\text { racy }\end{array}$} \\
\hline & & & & Input & Output \\
\hline$\overline{\text { Local }}$ & Low & Low & Low & High & High \\
\hline National & Medium & Medium & Medium & Medium & Medium \\
\hline Transnational & High & High & High & Low & Low \\
\hline Global & High & High & Low & Medium & Low \\
\hline
\end{tabular}


as follows: The lower the affective distance, the better the prospect of participation in e-democracy processes (see Table 1). Transferred to the spatial levels, this looks like an inverted U-shaped curve: a low affective distance on the local and global levels, and a higher affective distance on the national and transnational levels. This results in positive prospects on the local and global levels for participation in e-democracy processes and in rather negative prospects for the national and transnational levels.

\subsubsection{Hypothesis III (Output Hypothesis)}

We base the governance capacity or output dimension on the capacity of the polity responding fully to the needs of citizens. We assume more responsiveness in services and solutions to citizens' input on the local level than on the national, and relatively more on the national than on the transnational and global levels. Different reasons account for that: First, representatives on the local level might assume that citizens are better equipped to contribute to solutions to local problems or policies due to their affectedness and knowledge of local issues. Thus, for example, digital tools in which citizens report about damages in the streets can work only because of this very concrete knowledge. The bigger the scale gets, and the less knowledge about specific topics can be assumed for the collective as a whole, the less pressure exists for showing responsiveness in digital processes. Second, representatives in local polities know about the higher and more direct affectedness of the citizens by decisions of the local government. This might also apply for the national level, but less for the transnational and global levels. And third, from a practical perspective, the costs and time intensity for consultative or other digital tools on the local level are relatively lower than on the other levels, so solutions can be more easily and more efficiently achieved.

\section{Conclusion}

In the foregoing sections we introduced a new element for a better theoretical understanding of democracy in the digital age, namely the scale arguing that it accounts for the effectiveness of digital tools. We developed a conceptual framework to capture the spatial dimension in the first place - as distance in terms of territorial, cognitive, and affective distance. This is an attempt that so far has not been made and may constitute a basis for further development. Although the findings of meta studies corroborate our hypotheses, there remains the need for testing them. According to our overall argument, however, this testing should take into consideration the (vertical) comparison between the different levels in order to assess under which conditions of scale e-democracy has better chances of increasing citizens' participation and political actors' responsiveness, and thus democratic quality.

On the basis of the developed hypothesis, we contribute to the discussion of the still contentious impact of the Internet on the improvement of democratic quality. According to our argument, such an improvement would be based on more inclusion and more responsiveness in decision-making processes and policy solutions. The spatial perspective brings an innovative spin to the somewhat petrified positions on 
mobilizing or reinforcing effects of the Internet and a new theoretical argument for the debate on e-democracy in general. We found good reasons to assume that the chance of e-democracy tools mobilizing users beyond the patterns of offline participation is bigger on the local level as well as on the global level. In contrast, on the national and transnational levels we see more plausibility for the reinforcement thesis.

Remarkably, the discussion presented here of the scale of e-democracy again turns attention to the local level as in previous theoretical work on size and democracy. Against the background of the presented empirical findings, there is good reason to suppose that e-democracy projects on the local level are, in contrast to projects on the national or transnational level, more likely to mobilize a comparatively higher share of citizens. Furthermore, it appears that local governments are more open to the input of citizens than they are on the regional and national levels.

Our theoretical considerations suggest that distance matters when it comes to e-democracy and that future studies on the effectiveness and impact of e-democracy are well advised to account for the level on which it is focused. By introducing the theoretical argument of the spatial dimension of e-democracy, we do not disregard other important factors influencing the effectiveness of e-democracy tools such as usability, privacy and the like. We do not claim that distance is the only and most relevant factor.

The argument of scale obviously has practical implications also. Witnessing an increasing demand of citizens for more-and nonconventional forms of-involvement on one side and an increasing awareness of policy makers for this demand, it is relevant to examine on which level new and additional tools can successfully be implemented. Projects for e-democracy tools should take into consideration that each scale corresponds to a certain communication ecology that has to be addressed. One aspect that we could not cover in this article refers to the design of tools and features such as usability. According to our claim of scale, we argue that the design of an e-democracy tool has to be tailored to the level where it will be applied. A tool for a local community might entail different features from a tool on EU level. Thus, future studies should focus on the scale of e-democracy from theoretical, empirical, and practical perspectives.

Funding Open Access funding provided by Projekt DEAL.

Open Access This article is licensed under a Creative Commons Attribution 4.0 International License, which permits use, sharing, adaptation, distribution and reproduction in any medium or format, as long as you give appropriate credit to the original author(s) and the source, provide a link to the Creative Commons licence, and indicate if changes were made. The images or other third party material in this article are included in the article's Creative Commons licence, unless indicated otherwise in a credit line to the material. If material is not included in the article's Creative Commons licence and your intended use is not permitted by statutory regulation or exceeds the permitted use, you will need to obtain permission directly from the copyright holder. To view a copy of this licence, visit http://creativecommons.org/licenses/by/4. $0 /$.

\section{References}

Adams, Paul C., and Rina Ghose. 2003. India.com. The construction of a space between. Progress in Human Geography 27:414-437. 
Anderson, Ashley A., Dominique Brossard, Dietram A. Scheufele, Michael A. Xenos, and Peter Ladwig. 2014. The "nasty effect:" Online incivility and risk perceptions of emerging technologies. Journal of Computer-Mediated Communication 19:373-387.

Avram, Gabriela (ed.). 2015. Proceedings of the 7th international conference on communities and technologies-C\&T'15. New York: ACM Press.

Barber, Benjamin R. 1998. Wie demokratisch ist das Internet? In Internet \& Politik. Von der Zuschauerzur Beteiligungsdemokratie?, ed. Claus Leggewie, 120-133. Köln: Bollmann.

Barberá, Pablo, John T. Jost, Jonathan Nagler, Joshua A. Tucker, and Richard Bonneau. 2015. Tweeting from left to right: Is online political Communication more than an Echo Chamber? Psychological science 26:1531-1542.

Bell, Daniel. 1976. The coming of post-industrial society. A venture in social forecasting. New York: Basic Books.

Benkler, Yochai. 2006. The wealth of networks. How social production transforms markets and freedom. New Haven, London: Yale University Press.

Bennett, W.L. 2003. New media power. In Contesting media power: alternative media in a networked world, ed. Nick Couldry, James Curran, 17-37. Lanham, Boulder, New York, Toronto, Oxford: Rowman \& Littlefield.

Bennett, Lance, and Alexandra Segerberg. 2013. The logic of connective action. Digital media and the personalization of contentious politics. Cambridge: Cambridge University Press.

Bennett, W.L., and Alexandra Segerberg. 2012. The logic of connective action. Information, Communication \& Society 15:739-768.

Berkes, Fikret, Po Garden, Louis Lebel, Per Olsson, Lowell Pritchard, and Oran Young. 2006. Scale and cross-scale dynamics: governance and information in a multilevel world. Ecology and Society. https:// doi.org/10.5751/ES-01759-110208.

Bershadskaya, Lyudmila, Andrei Chugunov, and Dmitrii Trutnev. 2013. e-participation development. In Proceedings of the 7th International Conference on Theory and Practice of Electronic Governance-ICEGOV'13, ed. Jeanne Holm, 73-76. New York: ACM Press.

Bimber, Bruce Allen. 2003. Information and American democracy: Technology in the evolution of political power. Cambridge: Cambridge University Press.

Buchstein, Hubertus. 1996. Bittere Bytes. Cyberbürger und Demokratietheorie. Deutsche Zeitschrift für Philosophie 44:583-607.

Cairncross, Frances. 2001. The death of distance. How the communications revolution is changing our lives. Boston: Harvard Business School.

Castells, Manuel. 2000. The rise of the network society. Oxford: Blackwell.

Castells, Manuel. 2011. Communication power. Oxford: Oxford University Press.

Castells, Manuel. 2012. Networks of outrage and hope. Social movements in the internet age. Cambridge: Polity Press.

Chadwick, Andrew. 2013. The hybrid media system. Politics and power. New York: Oxford University Press.

Clift, Steven L. 2004. E-government and democracy: representation and citizen engagement in the information age.

Coe, Kevin, Kate Kenski, and Stephen A. Rains. 2014. Online and uncivil? Patterns and determinants of incivility in newspaper Website comments. Journal of Communication 64:658-679.

Coleman, James, and Vincent Price. 2012. Democracy, distance, and reach: the new media landscape. In Connecting democracy. Online consultation and the flow of political communication, ed. Stephen Coleman, Peter M. Shane, 23-44. Cambridge: MIT Press.

Coleman, Stephen, and Jay G. Blumler. 2009. The Internet and democratic citizenship. Theory, practice and policy. Cambridge: Cambridge University Press.

Coleman, Stephen, and Peter M. Shane (eds.). 2012. Connecting democracy. Online consultation and the flow of political communication. Cambridge: MIT Press.

Coleman, Stephen, and Donald F. Norris. 2005. A new agenda for e-democracy. SSRN Electronic Journal. https://doi.org/10.2139/ssrn.1325255.

Dahl, Robert A. 1989. Democracy and its critics. New Haven, London: Yale University Press.

Dahl, Robert A., and Edward R. Tufte. 1973. Size and democracy. Stanford: Stanford Univ. Press.

Dahlgren, Peter. 2005. The Internet, public spheres, and political communication. Dispersion and deliberation. Political Communication 22:147-162.

Dahlgren, Peter. 2009. Media and political engagement. Citizens, communication, and democracy. Cambridge: Cambridge University Press. 
Dahlgren, Peter. 2013. The political web. Media, participation and alternative democracy. Houndmills, Basingstoke, Hampshire, New York: Palgrave Macmillan.

Denters, Bas. 2002. Size and political trust: evidence from Denmark, the Netherlands, Norway, and the United Kingdom. Environment and Planning C: Government and Policy 20:793-812.

Diamond, Larry J. 2010. Liberation technology. Journal of Democracy 21:69-83.

Diamond, Larry J., and Marc F. Plattner (eds.). 2012. Liberation technology. Social media and the struggle for democracy. Baltimore: Johns Hopkins Univ. Press.

van Dijck, José. 2013. The culture of connectivity. A critical history of social media. Oxford, New York: Oxford University Press.

van de Donk, Wim B.H.J. (ed.). 2004. Cyberprotest. New media, citizens, and social movements. London, New York: Routledge.

Dubois, Elizabeth, and Grant Blank. 2018. The echo chamber is overstated: the moderating effect of political interest and diverse media. Information, Communication \& Society 21:729-745.

European Parliament. 2016. Potential and challenges of e-participation in the European Union.

Fedotova, Olga, Leonor Teixeira, and Helena Alvelos. 2012. E-participation in Portugal: evaluation of government electronic platforms. Procedia Technology 5:152-161.

Ferrara, Emilio, Onur Varol, Clayton Davis, Filippo Menczer, and Alessandro Flammini. 2016. The rise of social bots. Communications of the ACM 59:96-104.

Flaxman, Seth, Sharad Goel, and Justin M. Rao. 2016. Filter bubbles, echo chambers, and Online news consumption. Public Opinion Quarterly 80:298-320.

Fuchs, Dieter. 1997. Kriterien demokratischer Performanz in Liberalen Demokratien. Discussion Paper FS-III97-203. https://bibliothek.wzb.eu/pdf/1997/iii97-203.pdf. Accessed April 052020.

Garrett, R.K. 2009. Echo chambers online?: Politically motivated selective exposure among Internet news users. Journal of Computer-Mediated Communication 14:265-285.

Gerbaudo, Paolo. 2012. Tweets and the streets. Social media and contemporary activism. London: Pluto Press.

Gerring, John, and Dominic Zarecki. 2012. Size and democracy, revisited: DISC woking paper series.

Habermas, Jürgen. 2008. Ach, Europa. Frankfurt am Main: Suhrkamp.

Hague, Barry N., and Brian D. Loader (eds.). 1999. Digital democracy. Discourse and decision making in the information age. London: Routledge.

Hampton, Keith N. 2015. Persistent and pervasive community. American Behavioral Scientist 60:101-124.

Hardin, Russell. 1999. Do we want trust in government. In Democracy and trust, ed. Russell Hardin, Claus Offe, 22-41. Cambridge: Cambridge University Press.

Hennen, Leonhard (ed.). 2020. European e-democracy in practice. Cham: Springer.

Hindman, Matthew S. 2009. The myth of digital democracy. Princeton: Princeton University Press.

Jörke, Dirk. 2019. Die Größe der Demokratie. Über die räumliche Dimension von Herrschaft und Partizipation. Berlin: Suhrkamp.

Kim, Yong-Chan, Jung Joo-Young, and Sandra J. Ball-Rokeach. 2007. Ethnicity, place, and communication technology. Information Technology \& People 20:282-303.

Kneuer, Marianne. 2013. Bereicherung oder Stressfaktor? Überlegungen zur Wirkung des Internets auf die Demokratie. In Das Internet. Bereicherung oder Stressfaktor für die Demokratie?, ed. Marianne Kneuer, 7-32. Baden-Baden: Nomos.

Kneuer, Marianne. 2016. E-democracy. A new challenge for measuring democracy. International Political Science Review 37:666-678.

Kneuer, Marianne. 2019. E-Democracy. In E-Government und Netzpolitik im europäischen Vergleich, ed. Wolf J. Schünemann, Marianne Kneuer, 323-357. Baden-Baden: Nomos.

Kneuer, Marianne, and Sebastian Harnisch. 2016. Diffusion of e-government and e-participation in democracies and autocracies. Global Policy 7:548-556.

Kneuer, Marianne, and Saskia Richter. 2015. Soziale Medien in Protestbewegungen. Neue Wege für Diskurs, Organisation und Empörung? Frankfurt, New York: Campus.

Kreiss, Daniel. 2015. The problem of citizens. E-democracy for actually existing democracy. Social Media + Society 1:1-11.

Lauth, Hans-Joachim. 2011. Quality criteria for democracy. Why responsiveness is not the key. In Regression of democracy? Zeitschrift für Vergleichende Politikwissenschaft Comparative Governance and Politics., ed. Gero Erdmann, Marianne Kneuer, 59-80. Wiesbaden: VS.

Macintosh, Ann. 2004. Characterizing e-participation in policy-making. In Proceedings of the 37th Annual Hawaii International Conference on System Sciences, ed. Ralph H. Sprague. Los Alamitos: IEEE Computer Soc. 
Margolis, Michael, and David Resnick. 2000. Politics as usual. The cyberspace "revolution". Thousand Oaks: SAGE.

McCaughey, Martha, and Michael D. Ayers (eds.). 2003. Cyberactivism. Online activism in theory and practice. Hoboken: Taylor and Francis.

Meine, Jonas. 2017. Hybride Sozialräume durch digitale Netzwerkstrukturen im Stadtquartier. In Gestaltung des Sozial- und Gesundheitswesens im Zeitalter von Digitalisierung und technischer Assistenz, ed. Tim Hagemann, 19-34. Baden-Baden: Nomos.

Mossberger, Karen, and Caroline J. Tolbert. 2009. Digital excellence in chicago. A citywide view of technology use.

Mossberger, Karen, Caroline J. Tolbert, Daniel Bowen, and Benedict Jimenez. 2012. Unraveling different barriers to Internet use. Urban Affairs Review 48:771-810.

Mossberger, Karen, Caroline J. Tolbert, and William Franko. 2013. Digital cities. The Internet and the geography of opportunity. New York: Oxford University Press.

Mossberger, Karen, Caroline J. Tolbert, and Ramona S. McNeal. 2008. Digital citizenship. The internet, society, and participation. Cambridge: MIT Press.

OECD. 2001. OECD handbook on information, consultation and public participation in policy-making. Paris: OECD Publishing.

OECD. 2003. The e-government imperative. Paris: OECD Publishing.

O'Reilly, Tim, and John Battelle. 2009. Web squared: web 2.0 five years on. http://www.kimchristen.com/ wp-content/uploads/2015/07/web2009_websquared-whitepaper.pdf. Accessed 9 July 2019.

Oser, Jennifer, Marc Hooghe, and Sofie Marien. 2013. Is Online participation distinct from offline participation? A latent class analysis of participation types and their stratification. Political Research Quarterly 66:91-101.

Papacharissi, Zizi. 2004. Democracy online: civility, politeness, and the democratic potential of online political discussion groups. New Media \& Society 6:259-283.

Pariser, Eli. 2012. The filter bubble. What the Internet is hiding from you. London: Penguin Books.

Peixoto, Tiago, and Jonathan Fox. 2016. Background paper-when does ICT-enabled citizen voice lead to government responsiveness? World development report.

Rheingold, Howard. 1993. The virtual community. Homesteading on the electronic frontier. Cambridge: MIT Press.

Røiseland, Asbjørn, and Signy I. Vabo. 2019. Size and democracy revisited A critical discussion of the claimed trade-off between problem-solving capacity and citizen participation. Lex Localis-journal of Local Self-Government 17:285-298.

Rose, Lawrence E. 2002. Municipal size and local nonelectoral participation: findings from Denmark, the Netherlands, and Norway. Environment and Planning C: Government and Policy 20:829-851.

Rose, Gloria, Ira van Keulen, and Georg Aichholzer. 2020. Formal Agenda-Setting (European Level). In European e-democracy in practice, ed. Leonhard Hennen, 209-236. Cham: Springer.

Saco, Diana. 2002. Cybering democracy. Public space and the Internet. Minneapolis: University of Minnesota Press.

Saglie, Jo, and Signy Irene Vabo. 2009. Size and e-democracy: Online participation in Norwegian local politics. Scandinavian Political Studies 32:382-401.

Scharpf, Fritz W. 1999. Governing in Europe. Effective and democratic? Oxford: Oxford University Press.

Scharpf, Fritz W. 2003. Problem-solving effectiveness and democratic accountability in the EU. MPIfG working paper. Köln: Max-Planck-Institut für Gesellschaftsforschung.

Shane, Peter M. 2012. Online consultation and political communication in the era of Obama. An introduction. In Connecting democracy. Online consultation and the flow of political communication, ed. Stephen Coleman, Peter M. Shane, 1-20. Cambridge: MIT Press.

Shapiro, Andrew L. 2000. The control revolution: how the Internet is putting individuals in charge and changing the world we know. New York: Public Affairs.

Shirky, Clay. 2011. The political power of social media: Technology, the public sphere, and political change. Foreign Affairs 90:28-41.

Simon, Julie, Theo Bass, Victoria Boelman, and Geoff Mulgan. 2017. Digital Democracy. The tools transforming political engagement: Nesta.

Slane, Andrea. 2007. Democracy, social space, and the internet. Law Journal 57:81-104.

Stephens, Monica, and Ate Poorthuis. 2015. Follow thy neighbor. Connecting the social and the spatial networks on Twitter. Computers, Environment and Urban Systems 53:87-95.

Sunstein, Cass R. 2009. Republic.com 2.0. Princeton: Princeton University Press.

Sunstein, Cass R. 2018. Republic. Divided democracy in the age of social media. Princeton Oxford: Princeton University Press. 
Sylvester, Dari E., and Adam J. McGlynn. 2010. The digital divide, political participation, and place. Social Science Computer Review 28:64-74.

Tiemann-Kollipost, Julia. 2020. Political participation in the digital age. An ethnographic comparison between Iceland and Germany. Bielefeld: transcript.

Tucker, Joshua A., Yannis Theocharis, Margaret E. Roberts, and Pablo Barberá. 2017. From liberation to turmoil: social media and democracy. Journal of Democracy 28:46-59.

United Nations. 2010. E-government survey 2010: leveraging E-government at a time of financial and economic crisis.

United Nations. 2012. E-government survey 2012: executive summary.

United Nations. 2003. UN global E-government survey 2003. https://publicadministration.un.org/egovkb/ portals/egovkb/Documents/un/2003-Survey/unpan016066.pdf. Accessed 1 July 2019.

Wilhelm, Anthony G. 2000. Democracy in the digital age. Challenges to political life in cyberspace. New York: Routledge.

Withers, Charles W.J. 2009. Place and the "spatial turn" in geography and in history. Journal of the History of Ideas 70:637-658.

World Bank. 2002. The e-government handbook for developing countries. A project of infoDev and the center for democracy and technology.

Xenos, Michael, and Patricia Moy. 2007. Direct and differential effects of the Internet on political and civic engagement. Journal of Communication 57:704-718.

Zook, Matthew, Martin Dodge, Yuko Aoyama, and Anthony Townsend. 2004. New digital geographies: information, communication, and place. In Geography and technology, ed. Stanley D. Brunn, 155-176. Dordrecht: Springer. 